\title{
MÓDULO ELETRÔNICO DE CONTROLE PARA VÁLVULAS SOLENÓIDES
}

\author{
José Alberto Fracassi da Silva \\ Escola Politécnica, Universidade de São Paulo, Av. Prof. Luciano Gualberto, Travessa 3, 158, 05508-900 São Paulo - SP \\ Claudimir Lucio do Lago* \\ Departamento de Química Fundamental, Instituto de Química, Universidade de São Paulo, Av. Prof. Lineu Prestes, 748, \\ 05508-900 São Paulo - SP
}

Recebido em 18/10/01; aceito em 23/1/02

\begin{abstract}
ELECTRONIC MODULE FOR SOLENOID VALVE CONTROL. This technical note describes a new and simple electronic circuit for driving solenoid valves. The circuit is based on a single integrated circuit DRV103, which is able to drive resistive or inductive loads up to $1.5 \mathrm{~A}$. Switching of $12-\mathrm{V}$ loads can be controlled by TTL-level signals in two distinct steps. Initially, $12 \mathrm{~V}$ is applied during $110 \mathrm{~ms}$, followed by $4.2 \mathrm{~V}_{\mathrm{RMS}}$ until the end of the activation TTL pulse. This mode of operation is particularly suitable to drive solenoids, because it requires a higher voltage to start and a lower maintenance voltage. By using this circuit, power consumption and heating are reduced and the solenoid lifetime is enhanced. Moreover, this circuit is specially appropriated to build computer-controlled solenoid valves systems.
\end{abstract}

Keywords: solenoid valve; flow injection analysis; instrumentation.

Solenóides são dispositivos eletromecânicos baseados no deslocamento causado pela ação de um campo magnético gerado por uma bobina e são muito utilizados na construção de outros dispositivos, como é o caso das válvulas para controle de fluidos. Existem diversos modelos de válvulas solenóides compreendendo uma grande faixa de dimensões e capacidades para controle desde pequenas vazões em equipamentos médicos e científicos até grandes plantas industriais. Em particular, as válvulas para baixas vazões (da ordem de mililitros por minutos) e baixas pressões têm sido amplamente aplicadas em equipamentos e montagens para uso em laboratórios clínicos e químicos. Elas são de pequenas dimensões e requerem baixa tensão e corrente de acionamento.

A estratégia para fechamento e abertura dos canais fluídicos depende do fabricante, mas o princípio de acionamento elétrico é basicamente o mesmo, isto é, uma tensão de alguns volts é aplicada sobre um solenóide que faz com que um núcleo metálico ferromagnético se desloque, causando a alteração do estado da válvula. $\mathrm{O}$ núcleo ferromagnético comprime uma mola que é a responsável por deslocar o núcleo para sua posição original quando a corrente elétrica é interrompida.

O esforço mecânico sofrido pelo núcleo não é uniforme durante o período em que a válvula é acionada. No início o núcleo deve vencer o atrito das partes internas da válvula e comprimir a mola. Ao fim do percurso, o núcleo deve permanecer estático e, geralmente, a única força que se opõe a esta situação é a da mola. Como a força exercida pelo núcleo tem origem no campo magnético do solenóide, quanto maior a corrente, maior o campo magnético e, portanto, maior a força exercida pelo núcleo. Assim, pode-se perceber que, durante o período em que a válvula deve permanecer acionada, haveria uma necessidade maior de corrente no estágio inicial de acionamento e, posteriormente, apenas um valor suficiente para manutenção. Normalmente, a válvula pode ser alimentada continuamente com o mesmo valor inicial de corrente, porém isso leva a um consumo elevado de energia elétrica e provoca o aquecimento e conseqüente desgaste prematuro do dispositivo.

*e-mail: claudemi@iq.usp.br
Circuitos eletrônicos para controle de solenóide com dois estágios diferentes de correntes podem ser implementados com simplicidade com o uso de um resistor e um capacitor ou recorrer a estratégias mais elaboradas. As desvantagens da implementação simplificada são as grandes dimensões dos capacitores e resistores necessários, o consumo global de energia - pois embora a válvula seja poupada, o resistor é aquecido - e a dificuldade de um controle mais apurado das condições de cada estágio.

Como os problemas relacionados ao acionamento são encontrados em outros dispositivos eletromagnéticos, alguns fabricantes de componentes eletrônicos desenvolvem componentes que permitem realizar um controle bastante refinado com um número mínimo de componentes. Este é o caso do componente DRV103 lançado recentemente pela Burr-Brown, subsidiária da Texas Instruments (Dallas, Texas, EUA).

Trata-se de um circuito "surface mounting device" (SMD) de pequenas dimensões e que permite a implementação de diversas montagens de circuitos de modulação por largura de pulso (PWM). O circuito apresentado nesta nota não utiliza toda a potencialidade do componente, limitando-se a uma proposta que deve ser bastante útil para aqueles que implementam sistemas baseados em válvulas solenóides como FIA e SIA.

A Figura 1 mostra o diagrama do circuito eletrônico, o qual requer um número mínimo de componentes além do DRV103U. Este componente permite o acionamento de cargas até $1,5 \mathrm{~A}$, segundo o fabricante, podendo ser substituído pelo DRV103H que suporta até 3 A.

A Figura 2 mostra de forma diagramática algumas tensões para um melhor entendimento. A Figura 2a mostra o pulso de controle. Este sinal é compatível com níveis TTL, de modo que microcomputadores e outros circuitos lógicos podem ser facilmente interfaceados. A Figura $2 b$ mostra a tensão sobre o solenóide. Durante o período inicial de acionamento $\Delta \mathrm{t}_{\mathrm{i}}\left(\mathrm{t}_{1}\right.$ até $\left.\mathrm{t}_{2}\right), 12 \mathrm{~V}$ contínuos são aplicados sobre o solenóide. A manutenção do acionamento é conseguida através de um trem regular de pulsos, de modo que em aproximadamente $33 \%$ do período, $12 \mathrm{~V}$ são aplicados, permanecendo em $0 \mathrm{~V}$ nos $67 \%$ restantes. Durante o intervalo de $t_{2} a_{3}$, o 


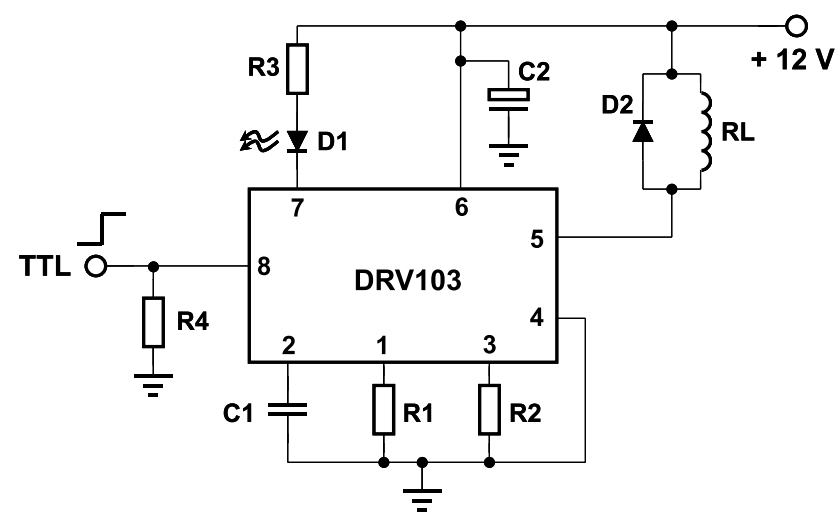

Figura 1. Circuito eletrônico de acionamento das válvulas. Resistores: RI - $130 k \Omega, R 2-205 k \Omega, R 3-5,1 k \Omega$ e R4- $10 k \Omega$; capacitores: $C 1-100 n F$ (cerâmico) e C2 - $22 \mu \mathrm{F} / 20 \mathrm{~V}$ (tântalo); diodos: D1 - LED FLV110 e D2 1N4001; RL indica as bobinas das válvulas solenóide, que devem ser ligados em paralelo para acionamento simultâneo. Todos os resistores utilizados foram de $1 \%$ de tolerância

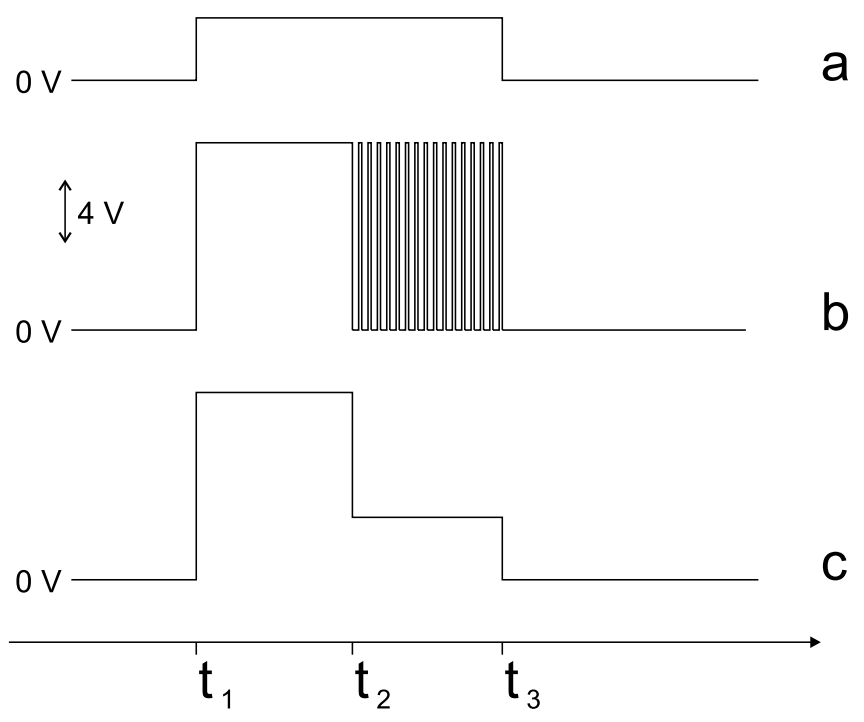

Figura 2. Diagrama esquemático de acionamento. (a) Pulso de acionamento (compativel com sinais TTL); Tensão real (b) e efetiva (c) sobre as bobinas das válvulas

solenóide é submetido a uma tensão efetiva (Figura 2c) igual a 33\% do valor máximo aplicado, isto é, 4,0 V. Esta tensão efetiva pode ser variada alterando-se a porcentagem do ciclo em que a tensão máxima é aplicada. Isto é conseguido alterando-se o valor de $\mathrm{R}_{1}$. Já o período inicial de acionamento pode ser controlado alterando-se $\mathrm{C}_{1}$. A freqüência do sinal no período de manutenção é ajustada por $R_{2}$. O intervalo inicial é determinado por:

$\Delta t_{i}=1,1 \cdot 10^{6} \cdot \mathrm{C}_{1}$

$\mathrm{O}$ resistor $\mathrm{R}_{2}$ é determinado por

$\mathrm{R}_{2}=\frac{6,81 \cdot 10^{9}}{f^{1.0288}}$ onde f é a freqüência de oscilação dada em $\mathrm{Hz}$. O resistor $\mathrm{R}_{1}$ é determinado por

$R_{1}=(67,46+1,41 \cdot P) \cdot 10^{3}$

onde $\mathrm{P}$ é a porcentagem ativa do ciclo. A equação 3 é válida a $25 \mathrm{kHz}$. Para outras frequiências, o manual do componente deve ser consultado ${ }^{1}$.

A principal vantagem do uso de PWM para controle da tensão efetiva aplicada sobre o solenóide é que um mínimo de potência é dissipado sobre o componente de controle, neste caso, o DRV103. Assim, em condições normais, o aquecimento do módulo de controle é mínimo. Contudo, se houver uma condição de sobre-corrente ou superaquecimento, o LED $\mathrm{D}_{1}$ é aceso. Se o superaquecimento do circuito integrado ultrapassar $160^{\circ} \mathrm{C}$, a saída é desabilitada até que a temperatura retorne a $140{ }^{\circ} \mathrm{C}$.

Os componentes foram selecionados para o acionamento de uma ou mais válvulas do tipo 161T031 da NResearch (West Caldwell, NJ, EUA), que é bastante popular². Outros modelos de válvula do mesmo fabricante - com múltiplas vias, por exemplo - podem ser acionadas desde que o solenóide interno possua as mesmas características. Segundo informações do fabricante, o tempo de resposta da válvula é de $15 \mathrm{~ms}$ e a tensão de manutenção deve ser de no mínimo $1 / 3$ da tensão máxima ${ }^{3}$. Os componentes da Figura 1 foram selecionados para que um período inicial de $110 \mathrm{~ms}$ e 4,2 V de tensão efetiva durante a manutenção fossem atingidos e, assim, as condições mínimas para o acionamento são plenamente satisfeitas. Como o tempo de resposta da válvula é de $15 \mathrm{~ms}$, uma freqüência muito maior que $35 \mathrm{~Hz}$ deve ser utilizada. No caso do circuito da Figura 1, a frequiência é de $25 \mathrm{kHz}$.

Testes repetitivos foram conduzidos a fim de verificar o desempenho do circuito. Para tanto, quatro válvulas solenóides 161T031 foram conectadas em paralelo e utilizadas com carga para o circuito (RL). Um gerador de sinais FG-2002C (Goldstar, Korea) foi utilizado para gerar pulsos TTL de acionamento de $500 \mathrm{~ms}$ seguidos de $500 \mathrm{~ms}$ de período inativo (freqüência de $1 \mathrm{~Hz}$ ), durante um período total de $3 \mathrm{~h}$. Ao fim deste período, não foi notado qualquer indício de superaquecimento. Similarmente, várias outras condições de freqüência e largura relativa do pulso de acionamento não causaram superaquecimento.

Alguns tipos de injetores para FIA necessitam que três válvulas solenóides sejam acionadas simultaneamente. Com apenas um módulo de controle, estas três válvulas podem ser acionadas em paralelo, respeitando-se a capacidade máxima de corrente do módulo. Além disso, com pequenas modificações, o circuito pode ser reaproveitado em inúmeras outras aplicações envolvendo acionamento eletromecânico de 8 a $32 \mathrm{~V}$.

\section{AGRADECIMENTOS}

Ao CNPq e FAPESP pelos auxílios e bolsas concedidos e à Texas Instruments pelas amostras de componentes eletrônicos.

\section{REFERÊNCIAS}

1. http://www.ti.com, acessada em Janeiro 2002.

2. http://www.coleparmer.com, acessada em Janeiro 2002. A Cole-Parmer (Vernon Hills, IL, EUA) comercializa o mesmo tipo de válvula, sendo que todas aquelas das séries 01367 e 98300 podem ser acionadas com este circuito.

3. A NResearch (http://www.nresearch.com, acessada em Janeiro 2002) fabrica um módulo para acionamento de até 5 válvulas solenóides (CoolDrive) com características elétricas e temporais semelhantes às propostas neste trabalho. 